\title{
A well-testing method for parameter evaluation of multiple fractured horizontal wells with non-uniform fractures in shale oil reservoirs
}

\author{
Meiling Meng ${ }^{1}$, Zhiming Chen $^{1 \oplus *}$, Xinwei Liao ${ }^{1 \oplus *}$, Junlei Wang ${ }^{2}$, Lumin Shi $^{1}$ \\ ${ }^{1}$ School of Petroleum Engineering, China University of Petroleum, Beijing 102249, P. R. China \\ ${ }^{2}$ Research Institute of Petroleum Exploration and Development (RIPED), PetroChina, Beijing 100083, P. R. China
}

Keywords:

Shale oil

fracturing evaluation

well testing

non-uniform fracture

Cited as:

Meng, M., Chen, Z., Liao, X., Wang, J., Shi, L. A well-testing method for parameter evaluation ofmultiple fractured horizontal wells with non-uniform fractures in shale oil reservoirs. Advances in Geo-Energy Research, 2020, 4(2): 187-198, doi: 10.26804/ager.2020.02.07.

\begin{abstract}
:
Owing to intricate geological and engineering factors, the hydraulic fractures in shale oil reservoirs sometimes are in heterogeneous and random lengths, which brings a difficulty in fracture estimation. To improve this situation, a simple and quick well-testing method is presented for fracturing evaluation and parameter estimation of multiple fractured horizontal wells with non-uniform fractures. The semianalytical method and Laplace transformation are used for model solution. With the proposed model, we estimate the properties of non-uniform fractures in shale oil wells from the Ordos Basin based on the buildup testing data. Results from the case studies show that there is a good relationship between fracturing treatment parameters and generated fracture properties, including fracture length and storativity ratio (or fracture volume ratio). The fracture parameter values increase with the increase in fracturing liquid volume, especially the inner region permeability and storativity ratio. When the fracturing liquid volume per stage increases by $200-300 \mathrm{~m}^{3}$, the fracture impacts are weaker on generated parameters, which indicates that there would be an optimized fracturing liquid volume in the field case.
\end{abstract}

\section{Introduction}

As the permeability of shale oil reservoir is extremely low, there is no economic productivity under natural production conditions. To acquire economic productivity, the horizontal well with large-scale fracturing technology is the most effective mean. Micro-seismic data shows that after the treatment of large-scale fracturing, complex fractures are generated around the wellbore (Liu et al., 2019). Property estimations of reservoir, fracture, and fluid are necessary for performance forecasting and plan designing of production wells (Cipolla et al., 2009; Dong et al., 2019). Undoubtedly, fracturing evaluation and parameter estimation are the preconditions of efficient development of shale resources. As some researchers concluded that fracture properties had great influence on productivity of multiple fractured horizontal wells (MFHW) in shale oil reservoir, such as fracture number, fracture length, and fracture permeability or conductivity.

However, owing to intricate geological and engineering factors, the fractures in shale oil reservoirs were very complex (Clarkson and Pedersen, 2010; Harikesavanallur et al., 2010; Mayerhofer et al., 2010; Chen et al., 2018; Li et al., 2018a; Shakiba et al., 2018; Wang, 2019), which brings a difficult work for fracture estimation. Cipolla et al. (2009) presented a detailed description of the complex fracture morphology formed in shale reservoirs. Their work showed that the complex fractures were developed with arbitrary length and nonunique fracture conductivities.

The fracture identification techniques are generally divided into three main groups including direct far field approaches, direct near-wellbore approaches, and indirect approaches (Cipolla and Wright, 2000), as shown in Fig. 1. These techniques are more and more mature to identify single bi-wing fracture. However, as mentioned above, owing to intricate geological and engineering factors, the fractures in shale oil reservoirs are very complex, which brings a difficult work for fracture estimation. Fisher et al. (2002) evaluated

\footnotetext{
${ }^{*}$ Corresponding author.

E-mail address: 532394439@qq.com (M. Meng); zhimingchn@163.com (Z. Chen); xinwei@cup.edu.cn (X. Liao); wangjunlei@ petrochina.com.cn (J. Wang); shiluming222@163.com (L. Shi). 2207-9963 (C) The Author(s) 2020.

Received April 2, 2020; revised April 22, 2020; accepted April 23, 2020; available online April 28, 2020.
} 


\begin{tabular}{|c|c|c|c|c|c|c|c|c|}
\hline \multirow{2}{*}{ Group } & \multirow{2}{*}{ Diagnostic } & \multicolumn{7}{|c|}{ Ability to Estimate } \\
\hline & & Length & Height & Asymmetry & Width & \begin{tabular}{l|l} 
Azimuth & D
\end{tabular} & ip Volume & Conductivity \\
\hline \multirow{3}{*}{$\begin{array}{l}\text { Direct, Far } \\
\text { Field }\end{array}$} & $\begin{array}{l}\text { Surface Tilt Fracture } \\
\text { Mapping }\end{array}$ & & & & & & & \\
\hline & \begin{tabular}{|l|} 
Downhole Tilt Fracture \\
Mapping
\end{tabular} & & & & & & & \\
\hline & $\begin{array}{l}\text { Microseismic Fracture } \\
\text { Mapping }\end{array}$ & & & & & & & \\
\hline \multirow{6}{*}{$\begin{array}{c}\text { Direct, } \\
\text { Near- } \\
\text { wellbore }\end{array}$} & Radioactive Tracers & & & & & & & \\
\hline & Temperature Logging & & & & & & & \\
\hline & Production Logging & & & & & & & \\
\hline & \begin{tabular}{|l|} 
Borehole Image \\
Logging
\end{tabular} & & & & & & & \\
\hline & Downhole Video & & & & & & & \\
\hline & Caliper Logging & & & & & & & \\
\hline \multirow{3}{*}{ Indirect } & $\begin{array}{l}\text { Net Pressure Fracture } \\
\text { Analysis }\end{array}$ & & & & & & & \\
\hline & Well Testing & & & & & & & \\
\hline & Production Analysis & & & & & & & \\
\hline & May Determine & \multicolumn{4}{|c|}{ Can determine } & \multicolumn{3}{|c|}{ Can not Determine } \\
\hline
\end{tabular}

Fig. 1. Capabilities and limitations of fracture diagnostics (Cipolla and Wright, 2000).

fracture geometry and properties by micro-seismic monitoring technology. First, the ground and underground measuring instruments were used to obtain the micro-seismic monitoring data, and then the micro-seismic data was analyzed to determine fracture properties. Suliman et al. (2013) estimated the properties of reservoir and fracture based on micro-seismic data, and the reservoir was divided into three regions: the crushed area, the fracturing affected area, and the unstimulated area. Among them, the crushed area was estimated as the associated areas where micro-seismic events occurred, and the fracturing affected area was estimated as the areas where the formation permeability increased, and the unstimulated area was the original formation without fracturing treatment.

Then, a method coupled micro-seismic monitoring interpretation with production history match is applied for fracture estimation. Mayerhofer et al. (2010) thought that a threedimensional stimulated zone with complex fractures would be generated in the near-well region after a large-scale hydraulic fracturing. Then, based on the micro-seismic monitoring data and the history production data, they used history production matching method to evaluate the fracture parameters. Similarly, Cipolla et al. (2009) estimated the fracture parameters with micro-seismic technology and history matching of production data. In their work, the complex fractures were subdivided into proppant-filled and non-proppant-filled ones. Combining with micro-seismic data and history production data, the parameters of reservoir and fracture in unconventional reservoirs were obtained, based on a volume fracturing simulation method (Harikesavanallur et al., 2010).

Another effective technique for fracture evaluation is well testing interpretation, and the first step of well testing interpretation is model development. For instance, Lee and Brock (1986) proposed a trilinear-flow model for vertical fractured wells in infinite homogeneous reservoir. Later, Ozkan et al. (2011) and Brown et al. (2011) proposed trilinear-flow model for fractured horizontal well with three linear-flow regions including fracture flow, inter-fracture flow, and outer-region flow. Based on the trilinear flow, Stalgorova (2013) proposed the multi-linear flow model of fractured horizontal well in finite reservoir. Although the fracture topology and fracture interference cannot be reflected explicitly, these models have good advantages of fast calculation speed and strong adaptability.

Recently, Chen et al. (2016, 2019) proposed semianalytical models for multiple fractured horizontal well, and then they used well testing data and/or micro-seismic data to estimate the fracture geometries and properties of horizontal wells after large-scale fracturing treatments in shale reservoirs. However, the fractures in their work were mainly simple and bi-wing. Virtually, the fractures in shale reservoirs are in generally heterogeneous and random length, due to intricate geological and engineering factors. Wang et al. (2016) proposed a trilinear flow model for MFHW with considering fracture interferences, and their work provided a new perspective on pressure transient analysis in MFHW with a convenient and practical approach. Zhou et al. (2014), Chen et al. (2017), and Yu et al. (2018) proposed mathematical models of complex fractures for pressure/rate transient analysis. In their model, the fractures were with random geometries and properties. However, their works were mainly a theoretical work for well 


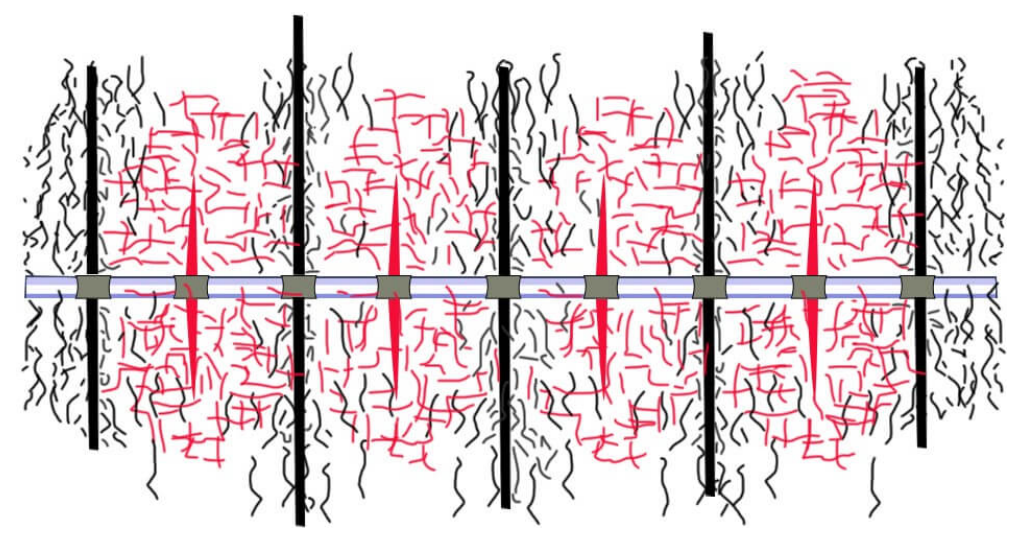

(a)

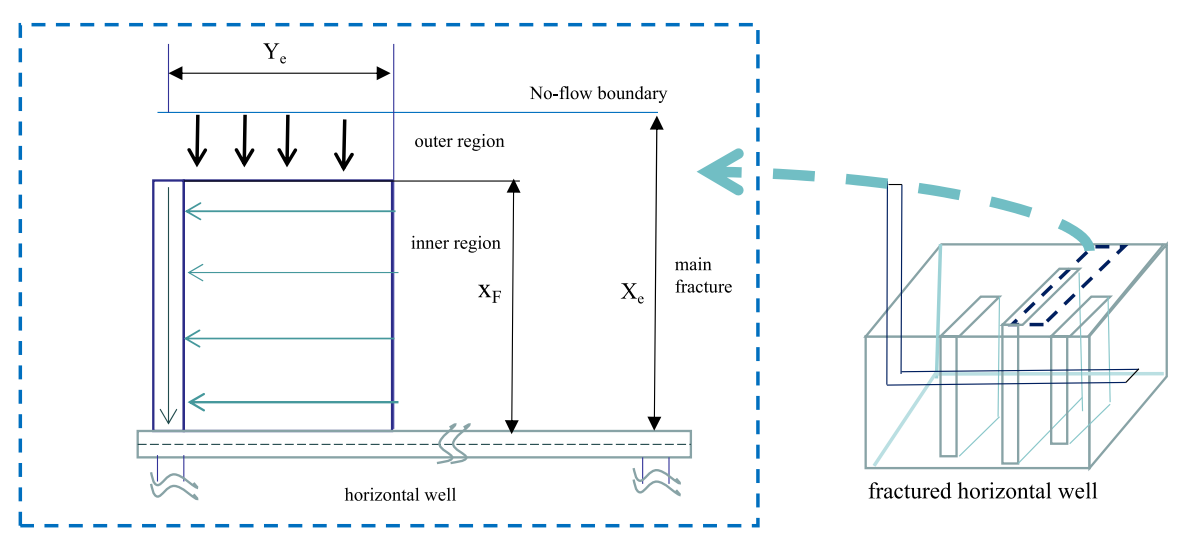

(b)

Fig. 2. (a) Schematic of a horizontal well after large-scale fracturing treatments (revised on Essca (2020)); (b) simplified MFHW with heterogeneous fractures.

testing, and model application was limitedly involved for fracturing evaluation and parameter estimation. Also, few works figure out the relationship between the fracturing treatment parameters and generated fracture parameters, based on well testing approach.

To improve this situation, a semi-analytical well-testing approach based on trilinear flow (Ozkan et al., 2011) was proposed in this work to identify the fracture properties. This work was organized as follows: (1) developing a well-testing model of MFHW with complex fractures including reservoir flow equations and fracture flow equations, (2) solving and verifying the proposed model by using Laplace transformation, superposition principle, and semi-analytical approach, (3) applying the well-testing model to case studies, and (4) estimating the fracture properties of shale oil wells from the Ordos Basin.

\section{Physical model}

\subsection{Conceptual model}

A multiple fractured horizontal well with complex fractures is located in the shale oil reservoir. The fractures are composed of main fractures and secondary fractures, with heterogeneous fracture half-length, as shown in Fig. 2(a). To facilitate model development, a simplified conceptual model is developed (Fig. 2(b)). As can be seen, the whole formation contains three distinct flow regions, namely (1) main fractures with arbitrary and non-unique lengths, (2) inner region with matrix and highpermeability secondary fractures, (3) outer region affected by hydraulic fracturing with lower permeability.

\subsection{Assumptions}

Given that the trilinear flow models have good advantages of fast calculation speed and strong adaptability, a semianalytical model is proposed for MFHW with heterogeneous fractures based on those models. In the semi-analytical model, each fracture is divided into multiple quarter-fractures (QFs) to describe the non-uniform fractures. Each QF has an independent drainage region, containing matrix, secondary fractures, and main fractures (Fig. 2(b)). Dual-porosity model is used to simulate the matrix system and secondary fracture system, with pseudo-steady state flow. The flow rates into the QFs are diverse. The flow modes contain the linear flow in main fractures, linear flow in inner region, and linear flow in outer region. The following assumptions are made for model development, including:

1) The reservoir is a horizontal, homogeneous, in rectangular shape with closed boundary.

2) Fluid is slightly compressible and single-phase, observing 


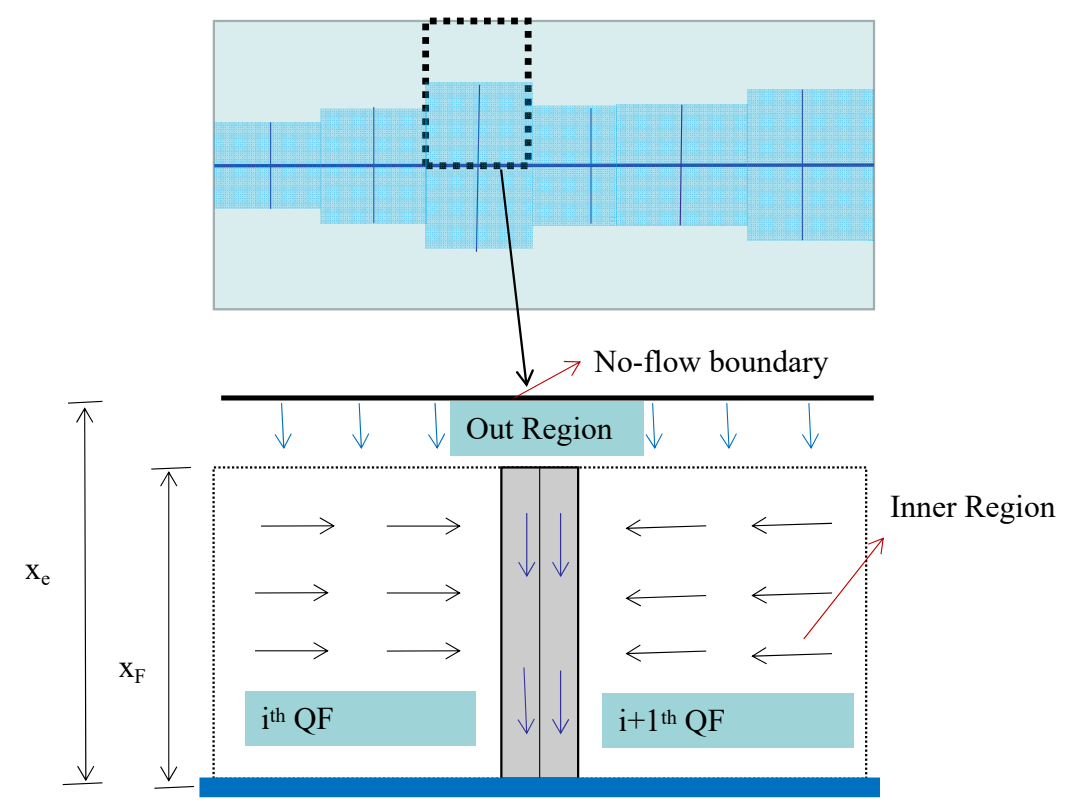

Fig. 3. Schematic of discretized MFHW model with complex fractures (revised from Wang et al. (2016)).

Darcy's law, the fluid flows in a planar slab, and the reservoir fluid can only flow from the main fracture to the wellbore.

3) The fractures with finite conductivity penetrate the entire reservoir completely.

4) The fracturing zone is coupled with the dual-porosity model, and the reservoir matrix fluid flows only to the secondary fracture network.

5) Effects of gravity and pressure loss within the horizontal wellbore are negligible.

6) The well produces at a constant rate and then falloff, taking into account the effects of wellbore storage and skin.

7) Fracture interferences are considered, and flow rates into the QFs are diverse.

\section{Mathematical model}

\subsection{Model development}

A semi-analytical model is developed for MFHW with heterogeneous fracture half-length. If we assume that the number of fractures is $n_{F}$, the number of QFs is $4 n_{F}$. Each $\mathrm{QF}$ is treated as production source, and then a superposition method is used to solve flow model. Details about the model development are discussed in the Appendix A.

Reservoir Flow. With the linear flows, the reservoir flow of outer region and inner region can be described as follows (Ozkan et al., 2011). First, the mass balance equation in the outer region is expressed as Eq. (1) with considering stresssensitivity effect:

$$
\left\{\begin{array}{l}
e^{-\alpha_{D} p_{O D}}\left[\frac{\partial^{2} p_{O D}}{\partial x_{D}^{2}}-\alpha_{D}\left(\frac{\partial p_{O D}}{\partial x_{D}}\right)^{2}\right]=\frac{\partial p_{O D}}{\partial t_{D}} \\
\left.p_{O D}\right|_{t_{D}=0}=0 \\
\left.\frac{\partial p_{O D}}{\partial x_{D}}\right|_{x_{D}=x_{e D}}=0,\left.p_{O D}\right|_{x_{D}=1}=\left.p_{I D}\right|_{x_{D}=1}
\end{array}\right.
$$

where $p_{O D}$ is the pressure in the outer region; $p_{I D}$ is the pressure in the inner region; $x_{D}$ is the distance in the $\mathrm{X}$ direction; $x_{e D}$ is the boundary distance in the X-direction; $t_{D}$ is the production time. Then, the mass balance equation in the inner region is expressed as Eq. (2) with considering stresssensitivity effect:

$$
\left\{\begin{array}{l}
e^{-\alpha_{D} p_{I D}}\left[\frac{\partial^{2} p_{I D}}{\partial y_{D}^{2}}-\alpha_{D}\left(\frac{\partial p_{I D}}{\partial y_{D}}\right)^{2}\right]+\left.\frac{e^{-\alpha_{D} p_{O D}}}{y_{e D} C_{R D}} \frac{\partial p_{O D}}{\partial x_{D}}\right|_{x_{D}=1} \\
=\lambda\left(p_{I D}-p_{m D}\right)+\omega \frac{\partial p_{I D}}{\partial t_{D}} \\
\left.p_{I D}\right|_{t_{D}=0}=0 \\
\left.\frac{\partial p_{I D}}{\partial y_{D}}\right|_{y_{D}=y_{e} p}=0,\left.p_{I D}\right|_{y_{D}=w_{F D} / 2}=\left.p_{F D}\right|_{y_{D}=w_{F D} / 2}
\end{array}\right.
$$

where $p_{F D}$ is the pressure in the main hydraulic fracture; $y_{D}$ is the distance in the Y-direction; $y_{e D}$ is the boundary distance in the Y-direction; $\alpha_{D}, C_{R D}$ are representatively stress-sensitivity coefficient and the dimensionless reservoir conductivity (see Appendix A); $\omega$ indicates storativity ratio; $\lambda$ indicates interporosity flow coefficient.

Main Fracture Flow. With Assuming linear flow within the hydraulic-fracture, the associated partial-differential equation and boundary conditions for the hydraulic fracture are 
given by:

$$
\left\{\begin{array}{l}
e^{-\alpha_{D} p_{F D}}\left[\frac{\partial^{2} p_{F D}}{\partial x_{D}^{2}}-\alpha_{D}\left(\frac{\partial p_{F D}}{\partial x_{D}}\right)^{2}\right] \\
+\left.e^{-\alpha_{D} p_{I D}} \frac{2}{C_{F D}} \frac{\partial p_{I D}}{\partial y_{D}}\right|_{y_{D}=w_{F D} / 2}=\frac{1}{\kappa_{F D}} \frac{\partial p_{F D}}{\partial t_{D}} \\
\left.p_{F D}\right|_{t_{D}=0}=0 \\
\left.\frac{\partial p_{F D}}{\partial x_{D}}\right|_{x_{D}=1}=0,\left.e^{-\alpha_{D} p_{F D}} \frac{\partial p_{F D}}{\partial x_{D}}\right|_{x_{D}=0}=-\frac{\pi q_{D}}{C_{F D}}
\end{array}\right.
$$

where $p_{F D}$ is the pressure in the main hydraulic fracture; $w_{F D}$ is the fracture width; $C_{F D}$ is the fracture conductivity; $\kappa_{F D}$ is the diffusivity ratio of hydraulic fracture to outer region.

\subsection{Model solution}

Pressure solution. Given that the value of $\alpha_{D}$ of shale formation is tiny, the zero-order perturbation solution $\eta_{D}$ can be used for replace with $p_{D}$ when considering stress-sensitivity effect (Pedrosa, 1986; Wang, 2014).

$$
p_{D}\left(r_{D}, t_{D}\right)=-\frac{1}{\alpha_{D}} \ln \left[1-\alpha_{D} \eta_{D}\left(r_{D}, t_{D}\right)\right]
$$

By coupling reservoir flow and matrix flow, we obtain the dimensionless pressure solution:

$$
\bar{\eta}_{w D}(s)=\frac{\pi \bar{q}_{D}}{C_{F D} \sqrt{f_{F}(s)}} \frac{1}{\tanh \left[\sqrt{f_{F}(s)}\right]}
$$

where

$$
\left\{\begin{array}{l}
f_{F}(s)=\frac{s}{\kappa_{F D}}+\frac{2 \sqrt{f_{I}(s)} \tanh \left[\sqrt{f_{I}(s)}\left(y_{e D}-\frac{w_{D}}{2}\right)\right]}{C_{F D}} \\
f_{I}(s)=\frac{\sqrt{s} \tanh \left[\sqrt{s}\left(x_{e D}-1\right)\right]}{y_{e D} R_{C D}}+\left[\omega s+\frac{(1-\omega) s \lambda}{s(1-\omega)+\lambda}\right]
\end{array}\right.
$$

If we assume that the number of fractures is $n_{F}$, the number of QFs is $4 n_{F}$. Each QF is treated as production source, then we can obtain the pressure solutions:

$$
\bar{\eta}_{w D}(s)=\frac{\pi \bar{q}_{i D}}{C_{F D} \sqrt{f_{F}(s)}} \frac{1}{\tanh \left[\sqrt{f_{F}(s)}\right]}, i=1,2, \ldots, 4 n_{F}
$$

Mass Balance Equation. This is a requirement on mass balance for all QF, namely, the total flow rate into QFs is equal to the constant production rate, then we obtained:

$$
\sum_{i=1}^{4 n_{F}} \bar{q}_{F D i}=\frac{1}{s}, i=1,2, \ldots, 4 n_{F}
$$

When coupling the pressure equations and mass balance equations, one can obtain a closed equation of $8 n_{F}$ and the same number of unknowns, namely a wellbore pressure $\bar{\eta}_{w D}$, $4 n_{F}$ flow rate into QF $\bar{q}_{F D}$. As can be seen, we have the same number of unknowns and equation sets are closed. By solving
Table 1. Input parameters for model verification.

\begin{tabular}{lll}
\hline Parameters & Values & Units \\
\hline Wellbore storage coefficient & 0 & $\mathrm{~m}^{3} / \mathrm{MPa}$ \\
Well radius & 0.1 & $\mathrm{~m}$ \\
Well length & 6000 & $\mathrm{~m}$ \\
Well location & 5 & $\mathrm{~m}$ \\
Fracture number & 30 & - \\
Skin factor & 0 & - \\
Thickness & 10 & $\mathrm{~m}$ \\
Porosity & 0.1 & - \\
Permeability & 0.01 & $\mathrm{mD}$ \\
Permeability & 1 & $\mathrm{mD}$ \\
Storativity ratio & 0.2 & - \\
Interporosity flow coefficient & 10 & - \\
Uniform fracture half-length & 100 & $\mathrm{~m}$ \\
Uniform Fracture conductivity & 1200 & $\mathrm{mD} \cdot \mathrm{m}$ \\
\hline
\end{tabular}

the equation system, we can obtain the wellbore pressure $\bar{\eta}_{w D}(s)$. Then, by applying the inversion of Pedrosa's substation, the wellbore pressure with stress-sensitivity effect is acquired.

Due to complex situations like chocking and damaged fracture face, the wellbore storage effect and skin effect are taken into account in convolution method (Ozkan et al. 2011). Finally, with the Laplace-inverse transformation, the Laplacedomain pressure solution is easily transformed into timedomain pressure solution:

$$
\bar{p}_{w D}\left(s, S, C_{D}\right)=\frac{S+s \bar{p}_{w D}(s)}{s+C_{D} s^{2}\left[s \bar{p}_{w D}(s)+S\right]}
$$

where $S$ and $C_{D}$ are respectively the skin effect factor and the dimensionless wellbore-storage coefficient. For a buildup testing, the well pressure is obtained with the superposition equation:

$$
\bar{p}_{w D, s h u t}=\bar{p}_{w D}\left(t_{p D}\right)-\bar{p}_{w D}\left(t_{p D}+\Delta t_{D}\right)+\bar{p}_{w D}\left(\Delta t_{D}\right)
$$

where $t_{p D}$ is the production time; $\Delta t_{D}$ is the buildup time after buildup; $\bar{p}_{w D \text {,shut }}$ is the dimensionless pressure increment after buildup; $\bar{p}_{w D}\left(t_{p D}\right)$ is the dimensionless pressure at the instant of buildup; $\bar{p}_{w D}\left(t_{p D}+\Delta t_{D}\right)$ is the pressure increase caused by production; $\bar{p}_{w D}\left(\Delta t_{D}\right)$ is the dimensionless wellbore pressure of buildup well.

\section{Model results}

To show the reliability of the proposed model, a model verification is performed based on a commercial well-testing software, KAPPA Saphir. Given that its trilinear flow model can only consider uniform fractures, a simplified case with pressure drop is used here, and the input parameters of the model verification are given in Table 1 . As can be seen, there is good match between the proposed model and commercial software (Fig. 4). 
Table 2. Input parameters to calculate the pressure behaviors of MFHW with heterogeneous fractures.

\begin{tabular}{llll}
\hline Type & Parameters & Values & Units \\
\hline \multirow{4}{*}{ Wellbore } & Wellbore storage coefficient & 0.15 & $\mathrm{~m}^{3} / \mathrm{MPa}$ \\
& Well radius & 0.09 & $\mathrm{~m}$ \\
& Well length & 1000 & $\mathrm{~m}$ \\
& Well location & 5 & $\mathrm{~m}$ \\
& Fracture number & 10 & - \\
& Skin factor & 0.01 & - \\
\hline \multirow{3}{*}{ Outer region } & Thickness & 10 & $\mathrm{~m}$ \\
& Porosity & 0.1 & - \\
& Permeability & 0.01 & $\mathrm{mD}$ \\
\hline \multirow{3}{*}{ Inner region } & Permeability & 1 & $\mathrm{mD}$ \\
& Storativity ratio & 0.1 & - \\
\hline \multirow{2}{*}{ Main hydraulic fracture } & Heterogeneous fracture half-length & $90,100,60,100,70$ & $\mathrm{~m}$ \\
\hline
\end{tabular}

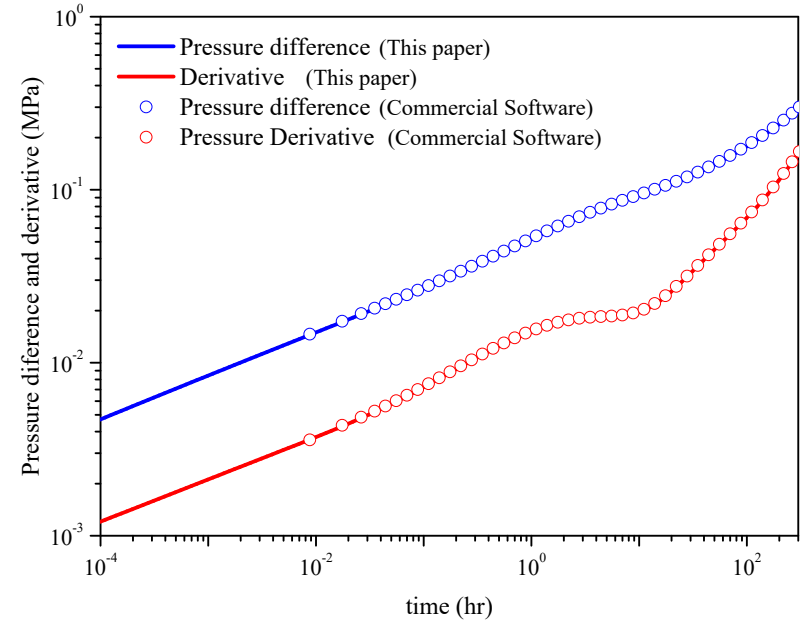

Fig. 4. Result comparison between the proposed model and commercial software.

Further, with the proposed model, the flow regimes of MFHW with heterogeneous fractures are identified during buildup testing. Based on the input parameters (Table 2), a $\log -\log$ graph of the calculated pressure difference and its derivative vs. time is obtained. The type curves are shown in Fig. 5.

It can be seen from Fig. 5 that the flow regimes of MFHW with heterogeneous fractures could be divided into:

1) Wellbore-storage stage and skin-effect stage (stage 1). Due to the wellbore storage effect, the pressure difference curve and the pressure derivative curve coincide at this stage and their slopes are 1 , which is determined by the wellbore storage coefficient. Then, the pressure derivative curve exhibits a "hump" characteristic after the end of a straight line with a slope of 1 . The skin factor dominates the height of "hump", with the wellbore storage coefficient.

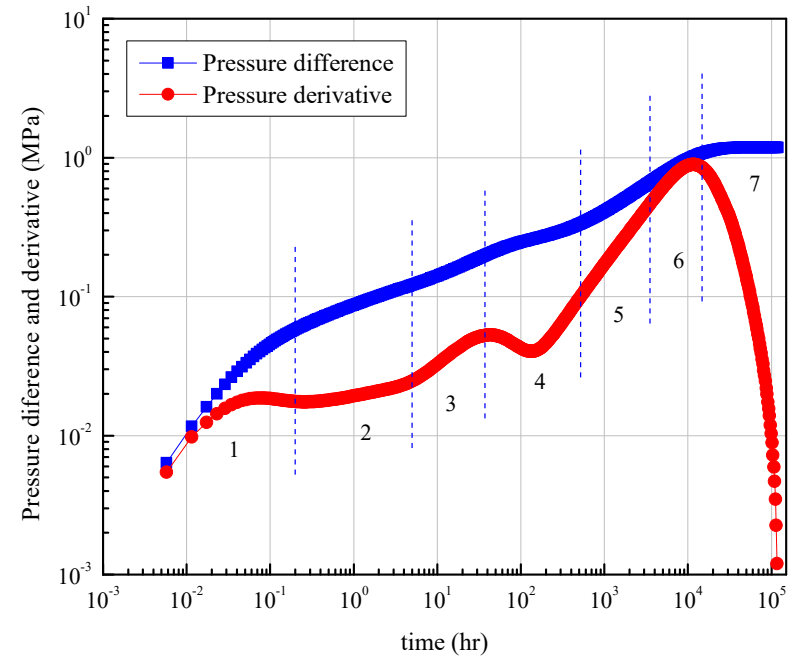

Fig. 5. Calculated pressure difference and its derivative vs. time. Different number refers to different flow stages.

2) Bilinear flow stage (stage 2). The pressure derivative curve behaves straight line with a slop of $1 / 4$. This stage reflects finite conductivity characteristic of main fractures. The parameters of main fractures can affect this stage, like half-length and conductivity.

3) Linear flow in the inner region (stage 3). A 1/2-slope straight line occurs in the pressure derivative curves at this stage, which shows the linear flow from inner region to main fracture.

4) Cross flow stage (stage 4). The "V-shape" of the pressure derivative curve reflects the inter-flow from the matrix to the secondary fractures in the inner region. This stage is mainly controlled by the storativity ratio and the interporosity flow coefficient.

5) Transition flow stage (stage 5). This stage reflects the transition flow from the inner region into outer region, and the pressure derivative shows a nearly-unit slope, 


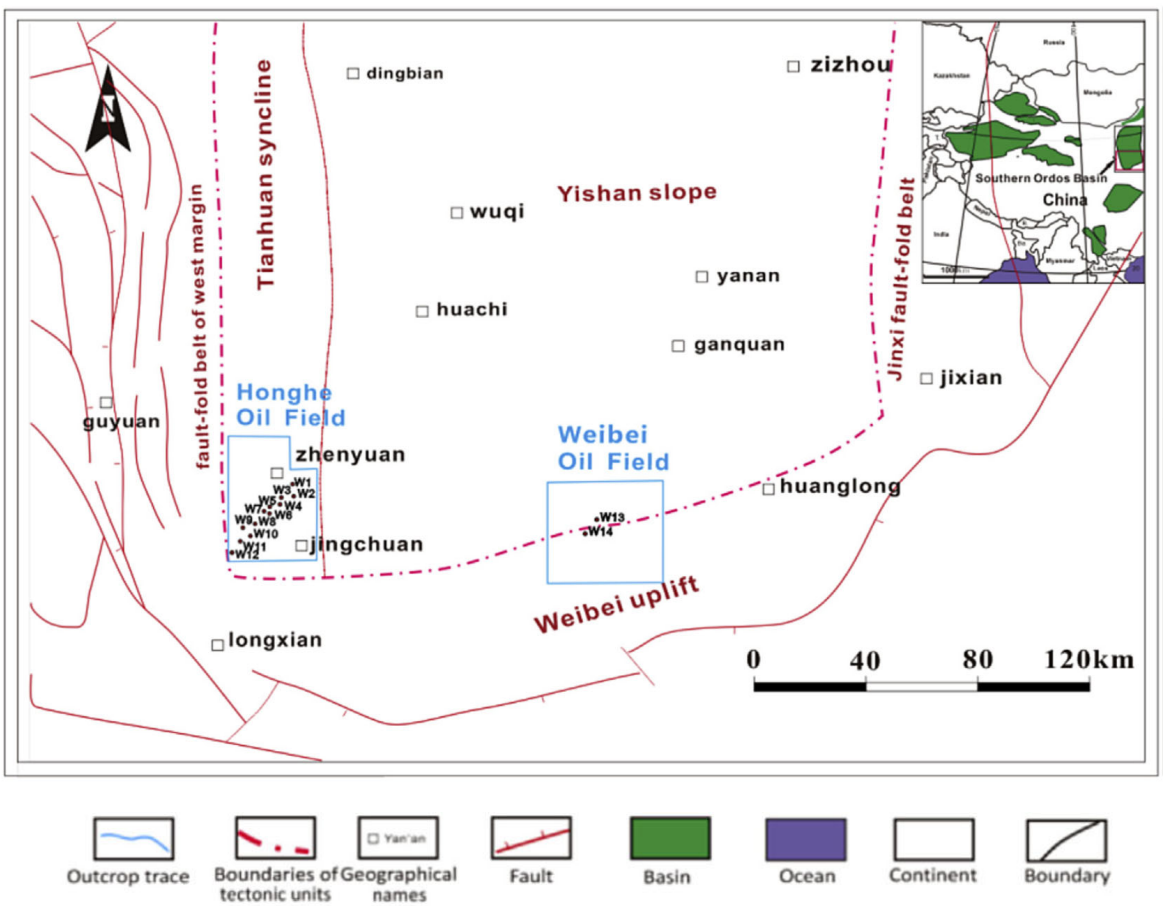

Fig. 6. Location of the HH oilfield of Yanchang Formation in Ordos Basin (Li et al., 2018b).

indicating that the transition flow occurs.

6) Linear flow in the outer region (stage 6). A 1/2-slope straight line occurs in the pressure derivative curves at this stage, which shows the linear flow from outer region into inner region.

7) Boundary dominated flow stage (stage 7). At this stage, the pressure derivative curve is falling off quickly. This stage indicates that the pressure wave has reached the boundary, occurring the boundary-effect flow and its occurrence time is controlled by the volume of the largescale fracturing formation.

\section{Model application}

\subsection{Geology background}

\section{Reservoir information.}

In this part, the case in $\mathrm{HH}$ oilfield is used for showing the model application of fracturing evaluation. The HH oilfield structure is located in Zhenyuan Jingchuan County in the south of Tianhuan Syncline from the Ordos Basin, as shown in Fig. 6 from $\mathrm{Li}$ et al. (2018b). It is a complex terrain area of Loess Plateau, with an average altitude of 1054-1486 m. It starts from Qingyang in the north, Ningxian in the south, Yima in the West, and Heshui in the East. The exploration area is about $4500 \mathrm{~km}^{2}$. There are five oil-bearing areas, including Banqiao, Shishe, Dongzhi, Baima, and Guchengchuan. The main production layer of $\mathrm{HH}$ oilfield is Chang 8 oil layer of Triassic system, with porosity of $3.9 \%-11 \%$, with an average value of $7.53 \%$. The permeability is ranging from 0.04 to $0.55 \mathrm{mD}$. The lithology has a certain influence on porosity and permeability. The porosity and permeability of tight sand- stone is significantly greater than that of fine sandstone, and the permeabilities of sandstones with the close porosity and granularity are also different, and the permeability of medium sandstones is higher than that of fine sandstone.

\section{Well information.}

There are lots of wells treated by hydraulic fracturing measurements to improve well productivity. Available well information is collected for case studies. Take for instance, Well A is a horizontal well located in HH oil-bearing area, and the production layer is Chang 8 , with horizontal wellbore of $798.82 \mathrm{~m}$, namely from $2405-3203.82 \mathrm{~m}$. Along the wellbore of Well A, there are 19 layers with poor comprehensive interpretation with accumulated length of $206.6 \mathrm{~m}$. Also, there are 37 dry layers with accumulated length of $116.8 \mathrm{~m}$ and 28 oil layers with accumulated length of $398.1 \mathrm{~m}$. Well B is also a horizontal well located in $\mathrm{HH}$ oil-bearing area in Chang 8, and its horizontal section length is $799.72 \mathrm{~m}$ (2208.28-3008 $\mathrm{m})$, with 33 poor oil layers of $320.3 \mathrm{~m}$ and 29 dry layers of $205.6 \mathrm{~m}$. Well A and Well B are respectively fractured by 12 and 7 stages. In the $\mathrm{HH}$ oil-bearing area, ten fractured wells, Well A to Well J, are selected for parameter evaluation due to available data.

\subsection{Parameter evaluation}

To evaluate the fracture parameters of Well A to Well J, the semi-analytical well testing model developed in this study is used to perform well test curve fitting on the buildup test data. By performing a series of type-curve matching, we obtain the evaluated parameters of the most-like fracture parameters, including the average fracture half-length, the average fracture conductivity, the storability ratio of secondary fractures, and 


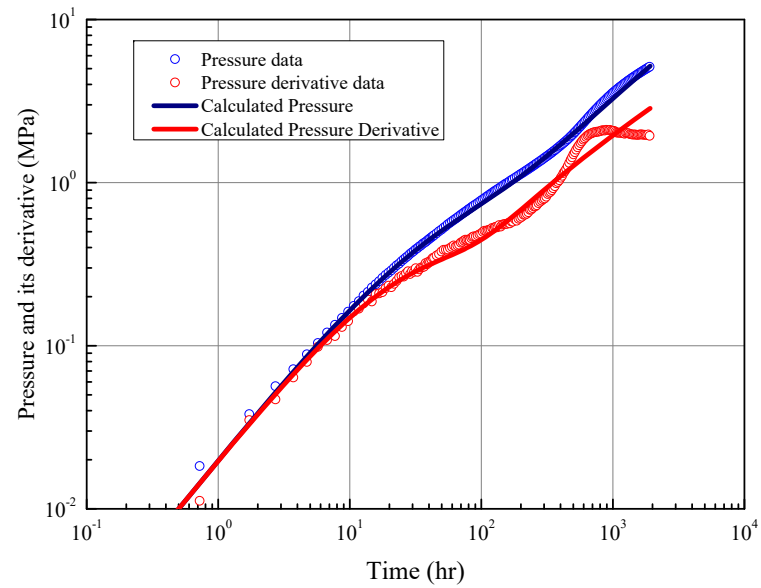

(a)

Fig. 7. Type-curve matching on pressure data.

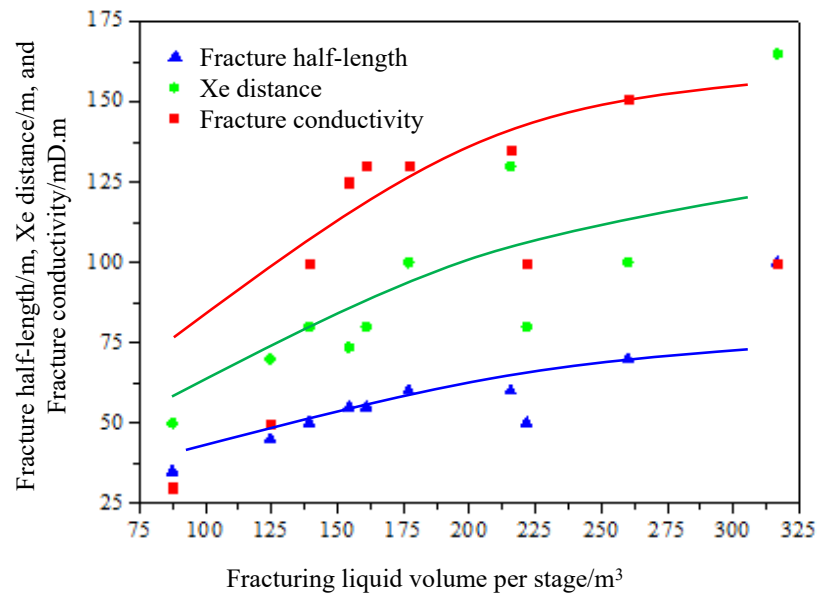

(a)

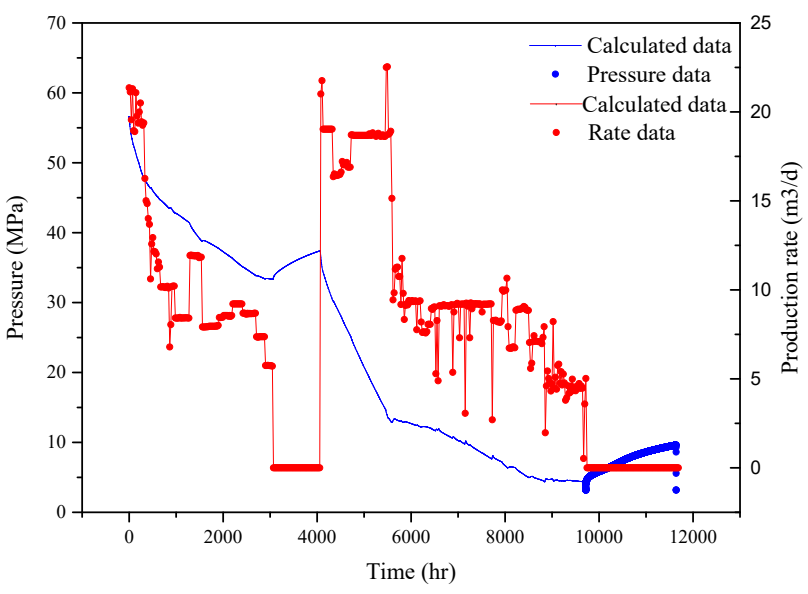

(b)

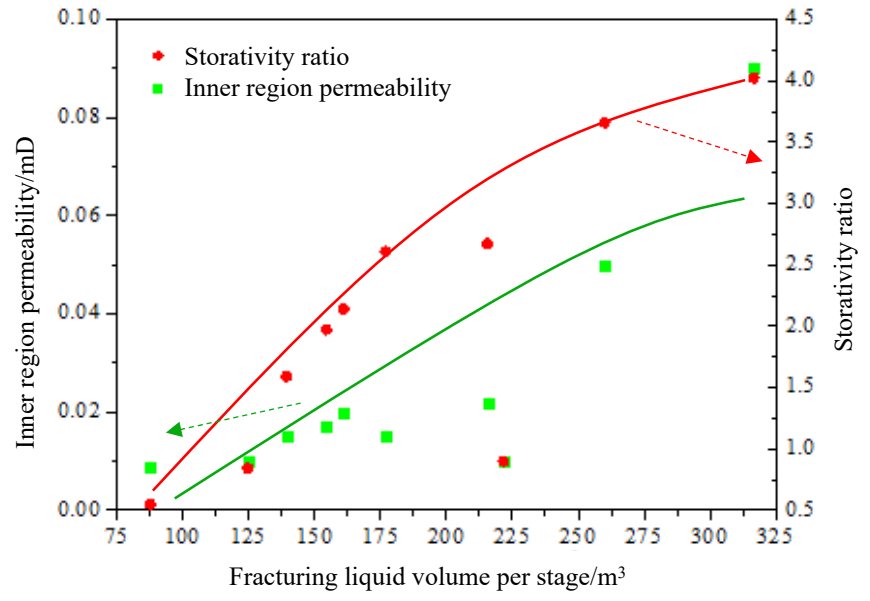

(b)

Fig. 8. Relationship between the fracturing liquid volume per stage and generated fracture parameters.

the interporosity flow coefficient, etc. Fig. 7 presents the typecurve matching on pressure data of Well A, and Table 3 provides the estimated properties of reservoir and fractures.

Further, the proposed semi-analytical well testing model is used to perform type-curve matching on the buildup test data of Well B to Well J. Table 4 provides the estimated results, and Fig. 8 plots the relationship between the fracturing liquid volume per stage and generated fracture parameters to better understand the fracturing effects. As can be seen, there is a good relationship between fracturing treatment parameters and generated fracture properties. The parameter values increase with the increase in fracturing liquid volume, including the fracture half-length, fracture conductivity, secondary fracture permeability, storativity ratio (or fracturing volume ratio), interporosity flow coefficient, and outer region permeability. The fracturing impacts on inner region permeability and storativity ratio (or fracturing volume ratio) are most obvious. When the fracturing liquid volume per stage increases by 200-300 $\mathrm{m}^{3}$, the fracture impacts are weaker on generated parameters, which indicates that there would be an optimized fracturing
Table 3. Evaluated fracture parameters of Well A.

\begin{tabular}{ll}
\hline Parameters & Values \\
\hline Average fracture half-length & $100 \mathrm{~m}$ \\
Average fracture conductivity & $100 \mathrm{mD} \cdot \mathrm{m}$ \\
Secondary fracture permeability & $4.02 \mathrm{mD}$ \\
Storativity ratio & $9 \%$ \\
Interporosity flow coefficient & $7.54 \times 10^{-10}$ \\
Outer region permeability & $0.009 \mathrm{mD}$ \\
\hline
\end{tabular}

liquid volume in the $\mathrm{HH}$ oilfield.

\section{Summary and conclusions}

Fracture evaluation based on a well-testing method of MFHW with non-uniform fractures in shale oil reservoirs are carried on in this study. The flow regimes showed by 
Table 4. Evaluated parameters of Well B to Well J.

\begin{tabular}{|c|c|c|c|c|c|c|c|c|c|c|}
\hline Type & Well name & B & $\mathrm{C}$ & $\mathrm{D}$ & $\mathrm{E}$ & $\mathrm{F}$ & G & $\mathrm{H}$ & I & $\mathrm{J}$ \\
\hline \multirow{3}{*}{ Fracture } & Number & 7 & 8 & 15 & 9 & 9 & 9 & 2 & 5 & 5 \\
\hline & Average half-length, $\mathrm{m}$ & 60 & 55 & 50 & 50 & 55 & 60 & 35 & 70 & 45 \\
\hline & Average fracture conductivity, $\mathrm{mD} \cdot \mathrm{m}$ & 135 & 125 & 100 & 100 & 130 & 130 & 30 & 151 & 50 \\
\hline \multirow{3}{*}{ Inner Region } & Permeability, mD & 2.67 & 1.97 & 1.59 & 0.90 & 2.14 & 2.61 & 0.55 & 3.66 & 0.84 \\
\hline & Storativity ratio & 0.022 & 0.017 & 0.015 & 0.010 & 0.020 & 0.015 & 0.009 & 0.050 & 0.010 \\
\hline & Interporosity flow coefficient & $\begin{array}{l}2.20 \mathrm{E}- \\
08\end{array}$ & $\begin{array}{l}1.66 \mathrm{E}- \\
08\end{array}$ & $\begin{array}{l}2.34 \mathrm{E}- \\
08\end{array}$ & $\begin{array}{l}1.00 \mathrm{E}- \\
06\end{array}$ & $\begin{array}{l}1.00 \mathrm{E}- \\
08\end{array}$ & $\begin{array}{l}2.50 \mathrm{E}- \\
08\end{array}$ & $\begin{array}{l}5.20 \mathrm{E}- \\
04\end{array}$ & $\begin{array}{l}1.00 \mathrm{E}- \\
08\end{array}$ & $\begin{array}{l}2.00 \mathrm{E}- \\
08\end{array}$ \\
\hline \multirow{2}{*}{ Outer Region } & Permeability, $\mathrm{mD}$ & 0.027 & 0.011 & 0.016 & 0.009 & 0.021 & 0.026 & 0.005 & 0.037 & 0.008 \\
\hline & Distance of $x_{e}, \mathrm{~m}$ & 130 & 73.6 & 80 & 80 & 80 & 100 & 50 & 100 & 70 \\
\hline
\end{tabular}

transient pressure behaviors of MFHW with heterogeneous fractures could be divided into: Wellbore-storage stage, skineffect stage, bilinear flow stage, linear flow in the inner region, cross flow stages, transition flow, linear flow in outer region, and boundary dominated flow.

The "V-shape" of the pressure derivative curve reflects the interporosity-flow from the matrix to the secondary fractures in the inner region. When the pressure derivative curve is falling off quickly, the boundary dominated flow stage occurs. This stage indicates that the pressure wave has reached the boundary, and its occurrence time is controlled by the outer region size.

There is a good relationship between fracturing treatment parameters and generated fracture properties. The fracture parameter values increase with the increase of fracturing liquid volume, especially the inner region permeability and storativity ratio. When the fracturing liquid volume per stage increases by 200-300 $\mathrm{m}^{3}$, the fracturing impacts are weaker on generated parameters, which indicates that there would be an optimized fracturing liquid volume in $\mathrm{HH}$ oilfield.

Of course, this is a primary work which tries to evaluate parameters of MFHW with non-uniform fractures in shale reservoirs. There are still some limitations in the proposed methodology, like complex fracture geometries, integrated workflow, and non-unique inversion solution, etc. More efforts still need to be made on these limitations in the next step.

\section{Nomenclature}

$C_{D}=$ dimensionless wellbore storage coefficient

$C_{F D}=$ dimensionless hydraulic fracture conductivity

$C_{R D}=$ dimensionless reservoir conductivity

$n_{F}=$ fracture number, integer

$h=$ reservoir thickness, $\mathrm{m}$

$x_{F}=$ hydraulic fracture length, $\mathrm{m}$

$w_{F}=$ fracture width, $\mathrm{m}$

$w_{D}=$ dimensionless fracture width, dimensionless

(D)

$K_{I}=$ natural fracture permeability in inner region, darcy

(D)

$K_{O}=$ natural fracture permeability in outer region, darcy

$K_{F}=$ hydraulic fracture permeability, darcy (D)

$p_{O}=$ pressure in outer region, $\mathrm{MPa}$
$p_{I}=$ pressure in inner region, $\mathrm{MPa}$

$p_{F}=$ pressure in hydraulic fracture, $\mathrm{MPa}$

$q=$ Flow rate, $\mathrm{m}^{3} / \mathrm{d}$

$t=$ production time, $\mathrm{h}$

$v=$ flow velocity, $\mathrm{m} / \mathrm{h}$

$y=$ coordinate, $\mathrm{m}$

$y_{e}=$ rectangle length of area around $1 / 4 \mathrm{HF}, \mathrm{m}$

$x=$ coordinate, $\mathrm{m}$

$x_{e}=$ rectangle width of area around $1 / 4 \mathrm{HF}, \mathrm{m}$

$s=$ Laplace transformation variable, dimensionless

$S=$ wellbore skin factor, dimensionless

\section{Greek}

$\alpha=$ permeability modulus, $\mathrm{MPa}^{-1}$

$\Delta=$ difference operator

$\phi=$ porosity, fraction

$\kappa_{I}=$ inner region diffusivity ratio

$\kappa_{O}=$ outer region diffusivity ratio

$\kappa_{F}=$ hydraulic fracture diffusivity ratio

$\mu=$ fluid viscosity, $\mathrm{mPa} \cdot \mathrm{s}$

$\omega=$ storage ratio, fraction

\section{Acknowledgement}

Thanks for the valuable comments from anyone to improve this work. We also thank the funding support from Beijing Natural Science Foundation (3204052), Science Foundation of China University of Petroleum Beijing (No. 2462018YJRC032), and National Major Project of China (2016ZX05047004).

\section{Conflict of interest}

The authors declare no competing interest.

Open Access This article, published at Ausasia Science and Technology Press on behalf of the Division of Porous Flow, Hubei Province Society of Rock Mechanics and Engineering, is distributed under the terms and conditions of the Creative Commons Attribution (CC BY-NC-ND) license, which permits unrestricted use, distribution, and reproduction in any medium, provided the original work is properly cited. 


\section{References}

Brown, M., Ozkan, E., Raghavan, R., et al. Practical solutions for pressure-transient responses of fractured horizontal wells in unconventional shale reservoirs. SPE Reserv. Eval. Eng. 2011, 14(6): 663-676.

Chen, H., Liao, X., Gao, J., et al. A well test analysis method for multi-stage fracturing horizontal wells in shale reservoirs. Xinjiang Petroleum Geology 2019, 40(3): 357-364. (in Chinese)

Chen, Z., Liao, X., Sepehrnoori, K., et al. A semianalytical model for pressure-transient analysis of fractured wells in unconventional plays with arbitrarily distributed discrete fractures. SPE J. 2018, 23(6): 2041-2059.

Chen, Z., Liao, X., Zhao, X., et al. A semianalytical approach for obtaining type curves of multiple-fractured horizontal wells with secondary-fracture networks. SPE J. 2016, 21(2): 538-549.

Cipolla, C.L. Modeling production and evaluating fracture performance in unconventional gas reservoirs. J. Pet. Technol. 2009, 61(9): 84-90.

Cipolla, C.L., Wright, C.A. Diagnostic techniques to understand hydraulic fracturing: What? why? and how? Paper SPE 59735 Presented at SPE/CERI Gas Technology Symposium, Calgary, Alberta, Canada, 3-5 April, 2000.

Clarkson, C.R., Pedersen, P.K. Tight oil production analysis: Adaptation of existing rate-transient analysis techniques. Paper SPE 137352 Presented at Canadian Unconventional Resources and International Petroleum Conference, Calgary, Alberta, Canada, 19-21 October, 2010.

Dong, P., Liao, X., Chen, Z., et al. An improved method for predicting $\mathrm{CO}_{2}$ minimum miscibility pressure based on artificial neural network. Adv. Geo-Energy Res. 2019, 3(4): 355-364.

Essca. http://essca.com/forum.php? $\bmod =$ viewthread\&tid=2104, 2020.

Fisher, M.K., Wright, C.A., Davidson, B.M., et al. Integrating fracture mapping technologies to optimize stimulations in the Barnett Shale. Paper SPE 77441 Presented at SPE Annual Technical Conference and Exhibition, San Antonio, Texas, 29 September-2 October, 2002.

Harikesavanallur, A.K., Deimbacher, F., Crick, M.V., et al. Volumetric fracture modeling approach (VFMA): Incorporating microseismic data in the simulation of shale gas reservoirs. Paper SPE 134683 Presented at SPE Annual Technical Conference and Exhibition, Florence, Italy, 19-22 September, 2010.

Lee, S.T., Brockenbrough, J.R. A new approximate analytic solution for finite-conductivity vertical fractures. SPE Form. Eval. 1986, 1(1): 75-88.

Li, Y., Yang, S., Zhao, W., et al. Experimental of hydraulic fracture propagation using fixed-point multistage fracturing in a vertical well in tight sandstone reservoir. J. Pet.
Sci. Eng. 2018a, 171: 704-713.

Li, Z., Wu, S., Xia, D., et al. An investigation into pore structure and petrophysical property in tight sandstones: A case of the Yanchang Formation in the southern Ordos Basin, China. Mar. Pet. Geol. 2018b, 97: 390-406.

Liu, R., Jiang, Y., Huang, N., et al. Hydraulic properties of 3D crossed rock fractures by considering anisotropic aperture distributions. Adv. Geo-Energy Res. 2018, 2(2): 113-121.

Mayerhofer, M.J., Lolon, E., Warpinski, N.R., et al. What is stimulated reservoir volume? SPE Prod. Oper. 2010, 25(1): 89-98.

Ozkan, E., Brown, M.L., Raghavan, R., et al. Comparison of fractured-horizontal-well performance in tight sand and shale reservoirs. SPE Reserv. Eval. Eng. 2011, 14(2): 248-259.

Pedrosa, O.A. Pressure transient response in stress-sensitive formations. Paper SPE 15115 Presented at SPE California Regional Meeting, Oakland, California, 2-4 April, 1986.

Shakiba, M., de Araujo Cavalcante Filho, J.S., Sepehrnoori, K. Using embedded discrete fracture model (EDFM) in numerical simulation of complex hydraulic fracture networks calibrated by microseismic monitoring data. J. Nat. Gas Sci. Eng. 2018, 55: 495-507.

Stalgorova, E., Mattar, L. Practical analytical model to simulate production of horizontal wells with branch fractures. Paper SPE 162515 Presented at SPE Canadian Unconventional Resources Conference, Calgary, Alberta, Canada, 30 October-1 November, 2012.

Suliman, B., Meek, R., Hull, R., et al. Variable stimulated reservoir volume (SRV) simulation: Eagle ford shale case study. Paper URTeC 2013-057 Presented at Unconventional Resources Technology Conference, Denver, Colorado, 12-14 August, 2013.

Wang, H.T. Performance of multiple fractured horizontal wells in shale gas reservoirs with consideration of multiple mechanisms. J. Hydrol. 2014, 510: 299-312.

Wang, H. Hydraulic fracture propagation in naturally fractured reservoirs: Complex fracture or fracture networks. J. Nat. Gas Sci. Eng. 2019, 68: 102911.

Wang, J., Jia, A., Wei, Y. A semi-analytical solution for multiple-trilinear-flow model with asymmetry configuration in multifractured horizontal well. J. Nat. Gas Sci. Eng. 2016, 30: 515-530.

Yu, W., Xu, Y., Weijermars, R., et al. A numerical model for simulating pressure response of well interference and well performance in tight oil reservoirs with complexfracture geometries using the fast embedded-discretefracture-model method. SPE Reserv. Eval. Eng. 2018, 21(2): 489-502.

Zhou, W., Banerjee, R., Poe, B.D., et al. Semianalytical production simulation of complex hydraulic-fracture networks. SPE J. 2013, 19(1): 6-18. 


\section{Appendix A}

In order to simplify the model solution, we define some dimensionless parameters:

Dimensionless pressure:

$$
p_{D}=\frac{K_{I} h}{1.842 \times 10^{-3} \mu q_{s c} B}\left(p_{i}-p_{j}\right), \quad j=m, I, O, F
$$

Storativity ratio and interporosity-flow coefficient:

$$
\omega=\frac{\left(\phi C_{t}\right)_{f}}{\left(\phi C_{t}\right)_{f}+\left(\phi C_{t}\right)_{m}}, \lambda=\alpha x_{F}^{2} \frac{k_{m}}{k_{f}}
$$

Dimensionless production time:

$$
t_{D}=\frac{3.6 K_{I} t}{\mu \phi C_{t} x_{F}^{2}}
$$

Dimensionless flow rate:

$$
q_{D}=\frac{q}{q_{s c}}
$$

Dimensionless distances:

$$
x_{D}=\frac{x}{x_{F}}, y_{D}=\frac{y}{x_{F}}, w_{F D}=\frac{w_{F}}{x_{F}}
$$

Dimensionless fracture conductivity and inner-region conductivity:

$$
C_{F D}=\frac{K_{F} w_{F}}{K_{I} x_{F}}, C_{R D}=\frac{K_{I} x_{F}}{K_{o} y_{e}}
$$

Dimensionless stress-sensitivity coefficient:

$$
\alpha_{D}=\frac{1.842 \times 10^{-3} q_{s c} \mu B}{K_{F} h} \alpha
$$

Dimensionless diffusivity ratios:

$$
\kappa_{o D}=\frac{\left(\frac{K}{\mu \phi C_{t}}\right)_{o}}{\left(\frac{K}{\mu \phi C_{t}}\right)_{I}}, \kappa_{F D}=\frac{\left(\frac{K}{\mu \phi C_{t}}\right)_{F}}{\left(\frac{K}{\mu \phi C_{t}}\right)_{I}}
$$

Flow in the outer region. With the linear flows (Ozkan et al., 2011), it is assumed that there is 1D flow in the X-direction in the outer reservoir. Because the matrix permeability is extremely low, we assume the boundary is sealed. The diffusivity equation and the associated boundary conditions for the outer reservoir are given by:

$$
\left\{\begin{array}{l}
e^{-\alpha_{D} p_{O D}}\left[\frac{\partial^{2} p_{O D}}{\partial x_{D}^{2}}-\alpha_{D}\left(\frac{\partial p_{O D}}{\partial x_{D}}\right)^{2}\right]=\frac{\partial p_{O D}}{\partial t_{D}} \\
\left.p_{O D}\right|_{t_{D}=0}=0 \\
\left.\frac{\partial p_{O D}}{\partial x_{D}}\right|_{x_{D}=x_{e D}}=0,\left.p_{O D}\right|_{x_{D}=1}=\left.p_{I D}\right|_{x_{D}=1}
\end{array}\right.
$$

Flow in the inner region. Compared with reservoir size, the effect of fracture width in inner reservoir is negligible. The flow rate in the Y-direction is assumed to be $1 \mathrm{D}$ and perpendicular to the hydraulic fractures. The diffusivity equation and associated boundary conditions for the inner reservoir are given by:

$$
\left\{\begin{array}{l}
e^{-\alpha_{D} p_{I D}}\left[\frac{\partial^{2} p_{I D}}{\partial y_{D}^{2}}-\alpha_{D}\left(\frac{\partial p_{I D}}{\partial y_{D}}\right)^{2}\right]+\left.\frac{e^{-\alpha_{D} p_{O D}}}{y_{e D} R_{C D}} \frac{\partial p_{O D}}{\partial x_{D}}\right|_{x_{D}=1}=\lambda\left(p_{I D}-p_{m D}\right)+\omega \frac{\partial p_{I D}}{\partial t_{D}} \\
\left.p_{I D}\right|_{t_{D}=0}=0 \\
\left.\frac{\partial p_{I D}}{\partial y_{D}}\right|_{y_{D}=y_{e D}}=0,\left.p_{I D}\right|_{y_{D}=w_{F D} / 2}=\left.p_{F D}\right|_{y_{D}=w_{F D} / 2}
\end{array}\right.
$$


Flow in the QF. With linear flow within the hydraulic-fracture, the diffusivity equation and boundary conditions for the hydraulic fracture are given by:

$$
\left\{\begin{array}{l}
e^{-\alpha_{D} p_{F D}}\left[\frac{\partial^{2} p_{F D}}{\partial x_{D}^{2}}-\alpha_{D}\left(\frac{\partial p_{F D}}{\partial x_{D}}\right)^{2}\right]+\left.e^{-\alpha_{D} p_{I D}} \frac{2}{C_{F D}} \frac{\partial p_{I D}}{\partial y_{D}}\right|_{y_{D}=w_{F D} / 2}=\frac{1}{\kappa_{F D}} \frac{\partial p_{F D}}{\partial t_{D}} \\
\left.p_{F D}\right|_{t_{D}=0}=0 \\
\left.\frac{\partial p_{F D}}{\partial x_{D}}\right|_{x_{D}=1}=0,\left.e^{-\alpha_{D} p_{F D}} \frac{\partial p_{F D}}{\partial x_{D}}\right|_{x_{D}=0}=-\frac{\pi q_{D}}{C_{F D}}
\end{array}\right.
$$

Using the Pedrosa's substitution (1986) and Laplace transformation, the zero order solution of pressure ( $\left.\eta_{D}\right)$ is used to eliminate the nonlinear effect. Then we can obtain: Flow in the outer region. The diffusivity equation and the associated boundary conditions for the outer reservoir are given by:

$$
\left\{\begin{array}{l}
\frac{\partial^{2} \bar{\eta}_{O D}}{\partial x_{D}^{2}}=s \bar{\eta}_{O D} \\
\left.\frac{\partial \bar{\eta}_{O D}}{\partial x_{D}}\right|_{x_{D}=x_{e D}}=0,\left.\bar{\eta}_{O D}\right|_{x_{D}=1}=\left.\bar{\eta}_{I D}\right|_{x_{D}=1}
\end{array}\right.
$$

Flow in the inner region. The diffusivity equation and associated boundary conditions for the inner reservoir are given by:

$$
\left\{\begin{array}{l}
\frac{\partial^{2} \bar{\eta}_{I D}}{\partial y_{D}^{2}}+\left.\frac{1}{y_{e D} R_{C D}} \frac{\partial \bar{\eta}_{O D}}{\partial x_{D}}\right|_{x_{D}=1}=s f(s) \bar{\eta}_{I D} \\
\left.\frac{\partial \bar{\eta}_{I D}}{\partial y_{D}}\right|_{y_{D}=y_{e D}}=0,\left.\quad \bar{\eta}_{I D}\right|_{y_{D}=w_{F D} / 2}=\left.\bar{\eta}_{F D}\right|_{y_{D}=w_{F D} / 2}
\end{array}\right.
$$

QF flow. The diffusivity equation and boundary conditions for the hydraulic fracture are given by:

$$
\left\{\begin{array}{l}
\frac{\partial^{2} \bar{\eta}_{F D}}{\partial x_{D}^{2}}+\left.\frac{2}{C_{F D}} \frac{\partial \bar{\eta}_{I D}}{\partial y_{D}}\right|_{y_{D}=w_{F D} / 2}=\frac{s}{\kappa_{F D}} \bar{\eta}_{F D} \\
\left.\frac{\partial \bar{\eta}_{F D}}{\partial x_{D}}\right|_{x_{D}=1}=0,\left.\frac{\partial \bar{\eta}_{F D}}{\partial x_{D}}\right|_{x_{D}=0}=-\frac{\pi \bar{q}_{D}}{C_{F D}}
\end{array}\right.
$$

$y$ coupling reservoir flow and matrix flow, we obtain the dimensionless pressure solution:

$$
\bar{\eta}_{w D}(s)=\frac{\pi \bar{q}_{D}}{C_{F D} \sqrt{f_{F}(s)}} \frac{1}{\tanh \left[\sqrt{f_{F}(s)}\right]}
$$

where:

$$
f_{F}(s)=\frac{s}{\kappa_{F D}}+\frac{2 \sqrt{f_{I}(s)} \tanh \left[\sqrt{f_{I}(s)}\left(y_{e D}-\frac{w_{D}}{2}\right)\right]}{C_{F D}}
$$

And

$$
f_{I}(s)=\frac{\sqrt{s} \tanh \left[\sqrt{s}\left(x_{e D}-1\right)\right]}{y_{e D} R_{C D}}+\left[\omega s+\frac{(1-\omega) s \lambda}{s(1-\omega)+\lambda}\right]
$$

